\title{
The Pros and Cons of Artificial Intelligence use in the Logistics Sector in Oman
}

\author{
Khadija Hassan Al Maqbali, Zouhaier Slimi, and Adela Balsa
}

\section{ABSTRACT}

This paper systematically discusses the impact of using AI in Oman's logistics sector and examines the opportunities and challenges of using AI in Oman's logistics sector. Besides, it suggests solutions for improving AI use in the logistics sector in Oman. The main objective of this paper is to investigate the impact of using AI in Oman's logistics sector. The specific objectives are to identify the opportunities for using AI in the logistics sector in Oman, identify the issues surrounding using AI in the logistics sector in Oman, and recommend possible solutions to improve the use of $\mathrm{AI}$ in the logistics sector in Oman. The study used both primary and secondary data based on mixed methods: quantitative and qualitative. The quantitative approach via a questionnaire tool to collect data from many respondents. The qualitative method has been observed using interviews and web articles to accumulate further information from people's opinions and thoughts. The outcomes indicated some advantages of $\mathrm{AI}$ : improving efficiency and reducing the challenges currently facing the logistics sector, diversifying the income sources, and enhancing Oman's economy. Findings revealed that the most significant AI challenges are unemployment, a long time and the high cost for implementation, lack of awareness of AI potentials, and requiring training with new skills. The findings came up with solutions related to educating students, spreading awareness, and training employees. The study has limitations such as insufficient information on the research subject, difficulties finding respondents who have enough experience to answer the questions efficiently, and time constraints.

Keywords: Artificial Intelligence, Challenges, Opportunities, Solutions.
Submitted : July 05, 2021

Published : July 27, 2021

ISSN: $2507-1076$

DOI: $10.24018 /$ ejbmr.2021.6.4.973

Khadija Hassan Al Maqbali

Logistics \& Transportation Management Department, International Maritime College Oman, Oman.

(e-mail: 003879-16@imco.edu.om)

Zouhaier Slimi

Foundation Department, International Maritime College Oman, Oman.

(e-mail: zouhaier@imco.edu.om)

Dr Adela Balsa

Logistics \& Transportation Management Department, International Maritime College Oman, Oman.

(e-mail: adela@imco.edu.om)

*Corresponding Author

\section{INTRODUCTION}

The logistics sector in Oman is playing a pivotal role in the promising modern economy. It has great importance in increasing incoming investments, non-oil exports, and the competitiveness of Oman. However, it is facing some limitations and challenges, either are visible or invisible, and that affects the decisions making directly. AI has affected most industries and the logistics industry without exception, and this development has revolutionised the logistics field. The most critical AI technology advancements are represented in autonomous vehicles, warehouse automation, predictive analytics, and intelligent roads. So, logistics partners can implement AI in several supply chain operations for a bright future for Oman.

\section{A. Background of the Study}

The rapid advancement of AI technologies has dramatically changed the world. AI can be a significant driver of economic growth and social progress. If industry, civil society, government, and the public work together to support technology development, thoughtful attention to its potential and managing its risks [1]. Therefore, the logistics industry's evolution has created the need for specialisation in AI technologies over the years. The logistics sector in Oman needs to adopt and implement AI technologies in different supply chain integration areas such as warehouses, manufacturers, ports, roads, and retailers. From the other side, the logistics companies must look at the limitations of applying AI among the partners and how to manage its risks to gain advanced solutions behind the use of AI.

\section{B. Statement of the Problem}

This study's primary focus is to evaluate the advantages and disadvantages of using AI in Oman's logistics sector to digitise and innovate ideal solutions in different logistics areas to benefit AI applications globally and regionally.

\section{Research Questions}

\section{Main questions}

1. What is the impact of using AI in the logistics sector in Oman?

\section{Sub questions}

1. What are the opportunities for using AI in the logistics sector in Oman?

2. What are the key challenges facing using $\mathrm{AI}$ in the logistics sector in Oman?

3. What are the optimal solutions and recommendations to 
improve using AI in the logistics sector in Oman?

\section{Research Objectives}

\section{The general objective}

1. This study's main objective is to investigate the impact of using $\mathrm{AI}$ in the logistics sector in Oman.

\section{The specific objectives}

1. To identify the opportunities for using AI in the logistics sector in Oman.

2. To identify the issues surrounding using AI in the logistics sector in Oman.

3. To recommend possible solutions to improve the use of $\mathrm{AI}$ in the logistics sector in Oman.

\section{E. Research Justification}

This study aims to conduct a case for applying AI in Oman's logistics sector to achieve its potentials globally and regionally. It will cover the opportunities and challenges beyond using $\mathrm{AI}$ in the logistics sector and improve AI practices in logistics companies to make the right decisions. The logistics experts are trying to fix different issues from the production point to the destination. Here AI has become a vital part of logistics and supply chain management worldwide. To overcome these challenges and increase the efficiency of the logistics sector in Oman, logistics companies can implement AI in different areas of the supply chain.

\section{F. Research Significance}

This topic is essential to understand how AI can enhance and improve Oman's logistics sector by looking at the advantages of $\mathrm{AI}$ and eliminating the issues that can face applying AI in the logistics field. The researcher believes that AI can make a massive impact on how it can simplify many operations by reducing time and costs and increasing the efficiency of the logistics sector. The outcome of this can contribute to the GDP of Oman and diversify the economic activities where the transition from one stage to another stage is not an easy process, and it is required time and money.

\section{G. Scope of the Research}

This study is conducted to evaluate the impact of using AI in the logistics sector in Oman through examine opportunities and challenges from using AI technologies and how to overcome these challenges to build a thriving logistics sector in Oman, and how can the concerned partners in this sector benefit from the applications of $\mathrm{AI}$ and in which areas can be implemented.

\section{H. Limitation of the Research}

The study has potential limitations. One of the most critical challenges that face the researcher is the lack of clear and accurate information. There is no adequate information on the research subject, which makes collecting information and data difficult. Additionally, when the researcher wants to gather data from the participants, the responses may not constitute the group they represent, so it is difficult to find persons who have enough experience to answer the questions efficiently. Furthermore, another limitation is the time constraint, and due to that, this study may not be conducted in a more significant sample of the community.

\section{LITERATURE REVIEW}

AI can be defined as a part of computer science concerned with constructing intelligent machines to perform tasks that usually require human intelligence [2]. "With the increasing popularity of AI technology, many modern logistics enterprises try to use AI technology to optimise the logistics link and improve the logistics efficiency" [3]. As it is known, $\mathrm{AI}$ is driving the fourth industrial revolution in different aspects of the world. Oman is one of the GCC countries that adopting digital transformation to optimise operations and improve efficiency. Oman's vision of 2040 is to drive the innovation that enhances economic growth and creates job opportunities in the present digital economy. This chapter will cover and answer the research questions concerned with the research's main topic. It needs literature to support the case and increase the value of the content to make it valid and reliable. Therefore, the literature needs to cover the opportunities or the advantages of using AI in the logistics sector, challenges facing using AI in the logistics sector, and the optimal solutions and recommendations to improve the use of AI in the logistics sector. Furthermore, it will include the literature gaps that faced the researcher while searching.

\section{A. The Opportunities for Using AI in the Logistics Sector in Oman}

The logistics companies in Oman can get a great advantage of using AI in different supply chains. Thus, there are some opportunities in which AI can be used to revolutionise the logistics sector. AI can provide the knowledge needed to decrease operations and inventory costs and having a quick response to customers means having satisfied clients. For example, two AI applications can be implemented in this case, including Intelligent Robotic Sorting, high-speed and effective sorting of letters, palletised shipment, and parcels. Another application is AI-Powered Visual Inspection, a machine that takes photos of the cargo using unique cameras identifying the damaged place and identifying the appropriate corrective action to fix that [4].

Additionally, AI can use Enhanced Customer Experience. It can change and improve the relationship between the logistics partners and their customers by personalising them. For instance, the cooperation between DHL Parcel and Amazon is an excellent example of a personalised customer experience. In this case, the delivery company offered the voice-based service to track the parcels and then get the shipment information using Amazon's Alexa-Powered Echo. Moreover, there are other advantages in which AI can improve the logistics sector, which are providing insights into improving the productivity of the supply chain management, having the ability to analyse massive volumes of data so boosting the accuracy of demand forecasting, improving the supplier selection and developing the supplier relationship management effectiveness, and improving factory scheduling and production planning [4]. Security is considered one of the biggest beneficiaries of AI technology, and here in Oman, AI has been implemented for image processing, facial recognition, and predictive analytics [5].

Companies can use AI technologies in manufacturing. This development has similarly appeared in Foxconn, which ranks first in EMS in the electronic industry. This company has developed 10,000 robots to balance the increase in labour 
costs in China. Another example is Japan, where it is one of the most leading countries in producing robots. Alteration of humans with the robot is followed in manufacturing that cannot prevent or stop since this technology embraces the low cost, high efficiency, and accuracy of the robot and will benefit the community on a vast level [6]. In addition, the usage of the robotic unit for data related repetitive tasks can provide largely perks for the companies. Amazon employs more than 100,000 warehouse robots that can take over human employees in different aspects. EY is one of the largest accounting firms, and its statistics claims that this can provide cost-saving up to $65 \%$ [7].

Moreover, in Andover, England, a large warehouse that runs primarily by robots can fulfil 65,000 orders, about 3.5 million grocery items in one week. This warehouse uses hivegrid-machine that is designed and built by British online grocer Ocado. The intelligent and automated warehousing system is completely capable of moving, lifting, and sorting the grocery items and then packaged and delivered by Ocado's employees [8].

UPS is one of the leading parcel delivery companies that use AI-powered GPS called ORION to find the fastest and the most cost-efficient route for its fleet. With the data and information given by the customers, drivers, and vehicles, ORION uses the algorithm to find out the appropriate way for each delivery. It is a real-time system that modulates the routes depending on the present traffic and other circumstances. Another company that has taken the idea of applying AI is Marble. It uses robots that work on the same AI system as automated cars (LIDAR) to deliver cargoes to consumers. Its feature is cutting down the risk of the driver, eco-friendly, and saving cost and time. Lineage Company uses AI to forecasts which items store a long time and stay in a short period. Based on that, the things that take a long time will be held on the back, and the others that will leave early will be kept in the front. As a result, Lineage has increased its efficiency by more than $20 \%$ [9].

In 2019, the technology sector at Oman Logistics Center in Asyad had made achievements to digitise Oman's logistics sector and innovative, intelligent solutions in different logistics operations to benefit AI applications globally and regionally. Asyad Group has launched an initiative to display and test the emerging and modern technologies to face the logistics challenges by communicating with more than 40 local and global companies and testing these technologies. One of these technologies was a diver robot, and it has been used in Sultan Qaboos Port. This technology helps diagnose the port infrastructure in depths and conditions that ordinary divers cannot withstand. Furthermore, in Suhar Port, drone technology was tested to identify and discover the damaged locations of berths and quay use AI to analyse the pictures captured by drones. Also, they used drones to deliver parcels in Muscat and Nizwa and use them in the warehouse inventories. More than that, Salalah Port has joined Tradelens Platform for tracking and tracing shipments across blockchain technology to take its benefits in tracking shipments, knowing shipments route and sharing its data with the other partners in the supply chain [10].

\section{B. The Key Challenges Facing Using AI in the Logistics Sector in Oman}

Although many benefits can be gotten from using AI, however, there must be challenges facing AI in the logistics sector, which must be considered. There is no escaping that $\mathrm{AI}$ is an expensive technology that requires a high cost of implementation because of the complexity of engineering that entering in building one AI machine or system. On the other side, the repair and maintenance of these technologies can cost thousands of dollars, not a small amount of money [11]. Moreover, AI needs human assistance, so AI cannot replace humans, and it is known that AI can do the works. Still, it is not an independent system and to ensure the efficiency of the results. There must be a need for human control and assistance [12]. Besides, AI can create the unemployment issue and reduce the workforce with the coming of these technologies. "When jobs are eliminated due to the integration of AI solutions, the company needs to either find new positions for their employees to take on or release them all together" [13]. So, logistics companies must consider this challenge before investing in AI replacement systems. According to a study conducted by McKinsey Global Institute [14], robots and intelligent agents could replace almost 30\% of the current human labour globally by 2030 . More than that, the study states that automation will replace between 400 million and 800 million individuals by the year 2030, which also requiring 375 million people to switch their occupational categories and learn new skills [14].

Additionally, AI cannot improve with experience. These machines cannot change their responses to the changing environments built for the repetitive work environment, and the input does not change. So, when there is some alteration in the information, the AIs need to be rebuilt, retrained, and reassessed. Furthermore, AI technologies cannot judge which is correct or incorrect because they are not understood the ethical and legal concepts where they have been programmed for situations; thus, they cannot make the right decisions in dealing with unfamiliar problems [11]. Furthermore, the other challenges facing $\mathrm{AI}$ in the logistics sector include operational costs, security issues, cybercrimes, lack of creativity, and long implementation time.

Al Busaidi [15], an operations officer at Injaz Oman, believes that AI might affect careers when the computers and their programs replace employees place as it sometimes happens in telecommunications companies and some institutes. These companies provide an electronic application that interacts with the user directly without the need of the employee. That may lead to the layoff of many employees and an increase in the number of job seekers [15].

Although many places in the market can use AI as the best substituent for traditional systems, the problem is AI knowledge. A portion of technology enthusiasts, researchers, and college students, only a few people are aware of AI potential. For instance, some small and medium enterprises can have their work scheduled or learn innovative methods to manage resources, increase their productivity, manage and sell products online, understand customer behaviour, and react effectively and efficiently to the market. Also, they are not aware of service providers like Google Cloud and Amazon Web Services [16]. 


\section{The Optimal Solutions and Recommendations to Improve Using AI in Oman's Logistics Sector}

There are many ways to improve using AI in the logistics sector. The logistics companies should combine machine learning automation and human data evaluation with their data to achieve high performance when the human staff and machines work together [17]. Additionally, private and public companies should examine how they can benefit from using AI and ML paths to help the community [1]. Moreover, Schools and universities should include ethics and related topics about AI, ML, computer science, and data science to create generations powered by technological progress. The logistics companies should hire skilled and experienced managers because the AI and ML should be guided by capable humans who can professionally implement the project management methodologies and the best practices [18]. According to Microsoft [17], the next generation of engineers must develop their skills in cutting edge new technologies to have an opportunity in working with institutions of the future. From the job loss side, the government and the private sector should understand the labour market nature and build it for the future where AI must be implemented to repurposes the energy in the labour market instead of making it redundant [5].

Furthermore, the use of AI in the business is not an easy process. Companies must have a structured approach that starts with determining business use cases with tremendous potential. They need to construct data ecosystems to warranty the AI algorithms success. Companies also should nurture the different capabilities and find methods to merge AI outcomes in the workflows, and employees should be educated and trained to adapt to AI successfully [19].

\section{Literature Gaps}

The researcher has found many valuable studies conducted with AI in the logistics and supply chain topics from different sources. From the opportunities for using the AI side, several studies provided examples of companies worldwide and how these companies benefit from using AIs. However, the researcher has not found enough information about $\mathrm{AI}$ in Oman's logistics sector. From the other side, the researcher has found a clear picture of the challenges that could face using AI in the logistics sector. Most studies agreed that the new technologies might create the unemployment issue. The researcher has found optimal solutions and recommendations from other researchers to prevent the challenges and improve using AI in the logistics sector with the solutions side.

\section{Methodology}

The systematic process of collecting and analysing data can be characterised by the analysis for a particular purpose where the methodology is used to investigate the questions of the study, and the methods used for the research are how data is obtained and analysed. This chapter describes the methodology used for collecting data and analysis answers the research questions related to the entire study. In more detail, it presents the research design, target population, and sampling techniques. It further outlines the data collection tools employed and data collection procedures, and it will be ended with data analysis.
The used methodology in the entire fundamental research is shown and summarised in the below diagram in Fig. 1.

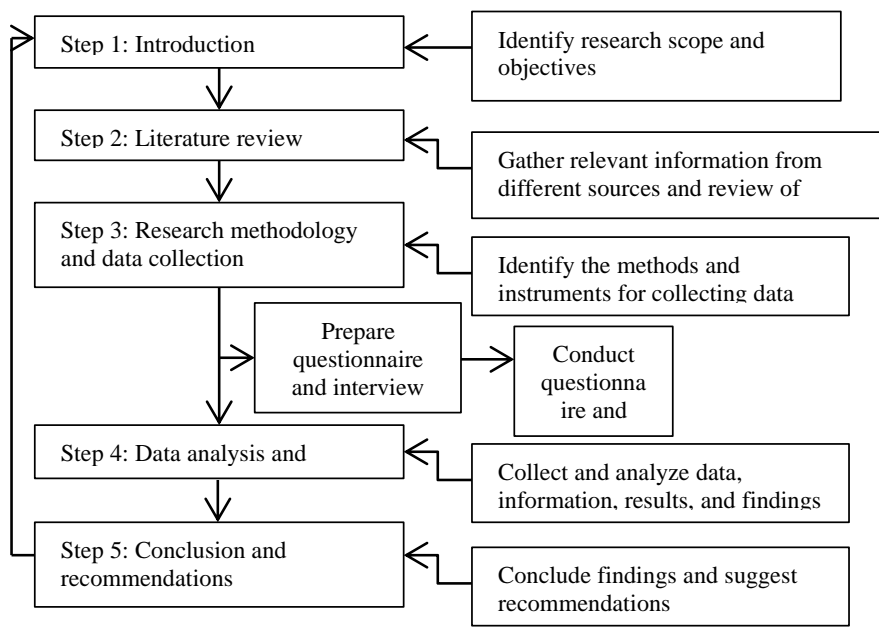

Fig. 1. The research framework.

\section{A. Research Design}

To meet the objectives and answer the questions, the researcher needs to choose the most appropriate design for this study's aim. For the fundamental research, the researcher will use mixed methods, including quantitative and qualitative methods, to strengthen the gathering of information and data collected to satisfy the readers and make it realistic and reliable. Moreover, some readers prefer dealing with linguistic and analytical data using both methods, while others prefer dealing with numerical data. Therefore, quantitative, and qualitative methods are used to support the findings shown in the next chapter.

The advantages of using mixed research method, according to Alex [20] are:

- Providing strengths to overcome the points of weakness for both ways, the quantitative and qualitative research.

- The researcher can have a broader range of research questions to gather a more authentic picture of a society with high validity.

- Providing a comprehensive and complete understanding of the research problem instead of using one kind of approach.

- Providing more precision and in-depth information and valuable datasets to the reader.

The disadvantages of using mixed research method, according to Alex [20] are:

- Taking much more time in organising the data and getting information from several sources.

- The research design can be more complex than using one kind of method.

- It requires careful and expert data analysis, and the interpretation can impact the research.

- It can be complicated to gather a large amount of data.

\section{B. Data Collection}

It is valuable to use mixed methods for this study because it will help the researcher strengthen the data accuracy rate by diversifying using other sources. For the quantitative method, the researcher will use a questionnaire tool, and for the qualitative approach, she will use the interview tool and 
website articles. From this approach, the researcher expects that the questionnaire will collect more information from different respondents. The interview will obtain and gather additional information from people's opinions and thoughts and collecting data from various website articles will provide a quicker and less expensive data collection. Fig. 2 highlights the research methodology instruments for this study.

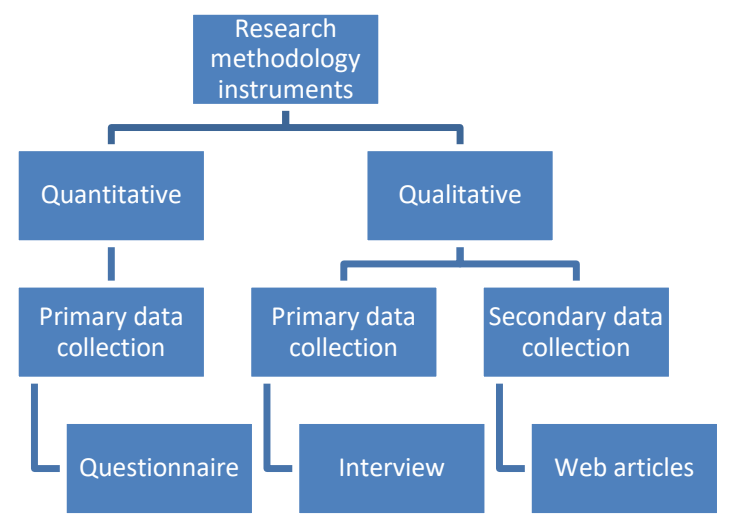

Fig. 2. Research methodology instruments.

There are some advantages of using the questionnaire in the research, which is easy to conduct large amounts of data and information can be obtained from many respondents, receiving responses through frank and anonymous ways, less time-consuming. Additionally, it can be easily reached to local, national, and international respondents, a cost-effective method. On the other side, there are several disadvantages of using the questionnaire in the research, and these include a low response rate. Respondents might interpret some questions in ways that are not relevant to the study. Furthermore, it is difficult to capture and identify feelings and emotional responses for respondents, and some questions can be challenging to analyse and require much more effort [21].

The interview will help obtain the highest response and gather complex and in-depth information. It also helps to explain the questions clearly and in detail and have the feedback with more clarification. On the negative side, it can be very costly and very time-consuming. Also, it is not practical with many respondents, and it might be challenging to summarise the interviewees' responses. The pilots' test is a crucial stage for the study. The researcher expects the respondents to cooperate and contribute to completing the collecting data and information process, which will appear positively on the study's results and findings. The researcher expects about $85 \%$ of responses will support and provide the target data and information for the study of using artificial intelligence in the logistics sector in Oman, pros and cons.

\section{Target Population and Sampling Techniques}

The researcher for the quantitative method targets the expertise of employees from different logistics institutes in Oman and students from various universities and colleges in Oman. While for the qualitative approach regarding the interview, the researcher targets two to three persons who work in Suhar port and students from IMCO. For the website articles, she is targeting Omani websites. The targeted participants' number is 150 , and the expected replies number is 100 . From the questionnaire side, the researcher will use a simple random sample from the population to find and analyse the data collected for the research by dividing the questionnaire into three parts covering the sub-questions, as is shown in the introduction chapter. Furthermore, the researcher will use an online survey, the most popular data collection source, and the questionnaire will be sent to the target sample in society. Also, the researcher will conduct online interviews to get more specific information and data about the study and look at different Omani web articles for further information and support findings.

\section{Data Analysis}

The primary sources for this study are interviews and questionnaires, and the secondary data sources will be collected from the website articles. For the questionnaire, the researcher will gather the data on the Office 365 Forms using different charts to illustrate and compare the data and get the results in the finding part. For the interviews, the researcher will use critical thinking to synthesise the data and then utilise these data from the interviews to corroborate the findings side with other questionnaire data. In addition, the web articles will support the ideas and thoughts of people to make the results more valid and reliable.

\section{FINDINGS AND ANALYSIS}

The main objective of this study is to investigate the impact of using $\mathrm{AI}$ in the logistics sector in Oman by identifying the opportunities for using AI, identifying the issues surrounding using AI, and recommending possible solutions to improve the use of AI in the logistics sector in Oman. Therefore, this chapter discusses the result of data analysis and findings that the researcher got from making questionnaires, interviews, and searching on web articles that are simulated the study, where the results are related to the research questions. This chapter focuses on collecting data by using qualitative and quantitative analysis. The findings are also discussed, considering the previous literature to identify the similarities and differences between this study and prior studies. So, the researcher will discuss and analyse the conclusions by summarising and emphasising the study's most important findings, which will help conclude the study with optimal solutions and recommendations.

\section{A. Findings}

The interview results are based on the research questions, and it was conducted with three persons. One of them works in Suhar port, and two persons were graduates of IMCO. Moreover, the researcher has looked at Omani web articles for further information and support findings. The researcher analysed the collected data based on three main headings: the opportunities for using AI in the logistics sector in Oman, the key challenges facing using AI in the logistics sector in Oman, and the optimal solutions and recommendations to improve using AI in Oman's logistics sector.

\section{The opportunities for using AI in the logistics sector in Oman}

The interview was conducted to obtain and gather additional information from people's opinions and thoughts A question indicates how AI can increase the efficiency of the logistics sector in Oman, and there were many valuable 
answers from interviewees. Speaker 1 (2021) stated that "AI makes the logistics operations fast in every field of logistics so that will lead to increase the efficiency of logistics in Oman". According to speaker 2 (2021), using AI saves time, fastening logistics operations, and meeting customer satisfaction. However, once these aspects are achieved, then the efficiency of the logistics sector will rise. On the side of speaker 3 (2021), using digital solutions and developing technologies in the logistics sector will increase the efficiency of this sector and that by speeding up the operations, decreasing costs and time, and satisfying the clients.

According to the results, Al Alawi stated a direct relationship between $\mathrm{AI}$ and its economy where the more the government relies on AI, the economy will rise. On the other hand, Al Bahri mentioned that the entry of AI in several industries like the automotive industry gives it a competitive advantage. Thus, its high prices will increase the country's revenues. Al Busaidi believes that the impact is through the quality of new products that rely on AI or reduce time. Hence, the product which is of high quality and low time is the cause to increase profits and decrease costs.

In the interview, there was a question related to evaluating the contribution of $\mathrm{AI}$ in decreasing the challenges currently facing the logistics sector. The interviewees have many opinions on that. According to speaker 1 (2021), many challenges are encountered in the logistics sector, such as delay, damage, and human mistakes. Still, with the contribution of AI, the challenges enormously will be decreasing. Speaker 2 (2021) said, "They have to employ AI in the warehouse in Oman to improve the operation of logistics, and AI can be used to reduce labour hours, which is a huge problem in the logistics industry. For example, people working in the warehouse must be working 24/7, which is not healthy and could cause harm to the workers either physically or mentally. Also, some warehouses have freezers that can reach up to -28. Imagine someone going to work tired and has to work in the freezer; he could collapse from being tired or because of the cold without being noticed". Speaker 3 (2021) noted, "As we all know that Coronavirus is destroying transportation, so killing the movement of logistics so by AI there will be time management, fast movement, and effective communication".

\section{The key challenges facing using AI in the logistics sector} in Oman

According to the interview results, there were different opinions of the impact of AI on employment. Speaker 2 (2021) stated, "As long as companies apply AI, the unemployment rate will increase because of depending on machines rather than manpower". Speaker 1 (2021) has the same opinion "AI will lead to reducing the opportunity of employment because the AI depends on technology". Speaker 3 (2021) has another belief "AI will increase employment opportunities and improve efficiencies because there will be new jobs in the future that adopt with the modern lifestyle means new opportunities".

On the other hand, Azzan Al Busaidi, an operations officer at Injaz Oman, mentioned that AI might create jobs and these jobs depend on people's skills which helps job seekers to go towards AI. Adding to that, Al Alawi stated that the impact of $\mathrm{AI}$ is between positive and negative. On the positive side, it may create new jobs on which the fourth industrial revolution and $\mathrm{AI}$ depend, and on the negative side, it may result in some institutions reduce their employees [15].

The researcher asked interviewees their opinions and thoughts about why AI requires high cost and a lengthy implementation, and there were several answers. Speaker 1 (2021) said, "As we know that AI depends on technology, and the technology is costly and needs time to establish". According to speaker 3 (2021), AI might be costly but will accelerate logistics. Speaker 2 (2021) said, "Because applying such a new system is expensive and the employees need effort and time to adapt with it".

According to the findings, there were different opinions on why most logistics sectors need to acquire new skills related to AI. According to speaker 2 (2021), logistics employees should always be ready to learn new skills to be open to the recent changes in the logistics world. She added, "I think it is important for every employee working in this sector to learn how to apply such a system to improve the efficiency of logistics and supply chain operations". Speaker 1 (2021) said, "Because AI has an especial process so, they have to be qualified". While speaker 3 (2021) said, "Because they need to improve work by new skills to make the work easier and improve the performance to get top positions in the logistics sector".

\section{The optimal solutions and recommendations to improve using AI in Oman's logistics sector}

The researcher has asked interviewees how educational institutions can improve AI for students, and there were different suggestions. According to speaker 2 (2021), they can educate them by simulating AI, conducting workshops, and adding this concept to logistics subjects. Speaker 1 (2021) said, "They have to give them lecturers about AI. Also, they have to take them to logistics fields to see how AI works". Speaker 3 (2021) stated, "I recommend that they should start teaching or training students about AI from the study stage so they can have enough knowledge and experience when it comes to the career". He added, there should be resorting to intelligent devices, improving the quality of education, and raising the efficiency of teachers.

According to the interview results, interviewees have additional recommendations to improve the use of AI in the logistics sector in Oman. Speaker 2 (2021) said, "They have to try applying such concept even by $30 \%$ to create a balance between human labour and the new system to increase the efficiency of logistics services and the productivity of the manpower". According to speaker 1 (2021), they must facilitate establishing AI. Also, they must find all requirements for AI. Speaker 3 (2021) stated, "employees and machines must be allowed to work together to increase efficiency and facilitate work quickly, ensure the use of technology in logistical operations, and train employees to use AI and cooperation between logistics companies and encourage the use of AI".

\section{B. Analysis}

The questionnaire is essential to collect data from many respondents, where the researcher distributed the questionnaire to employees from different logistics companies in Oman and students from other universities and colleges in Oman. The researcher analysed the questionnaire 
based on the participants' responses. The number of respondents was 102 , they are 23 males and 79 females, and most of the ages were ranging from 18 to 30 , and they were 97 , while 5 of the respondents their ages were ranging from $30-50$, and there were 0 respondents from the ages of above 50. Fig. 3 and 4 show charts of gender and age. The researcher also analysed the collected data in three main sections:

1. The opportunities for using AI in the logistics sector in Oman.

2. The key challenges are facing using AI in the logistics sector in Oman.

3. The optimal solutions and recommendations to improve using AI in Oman's logistics sector.

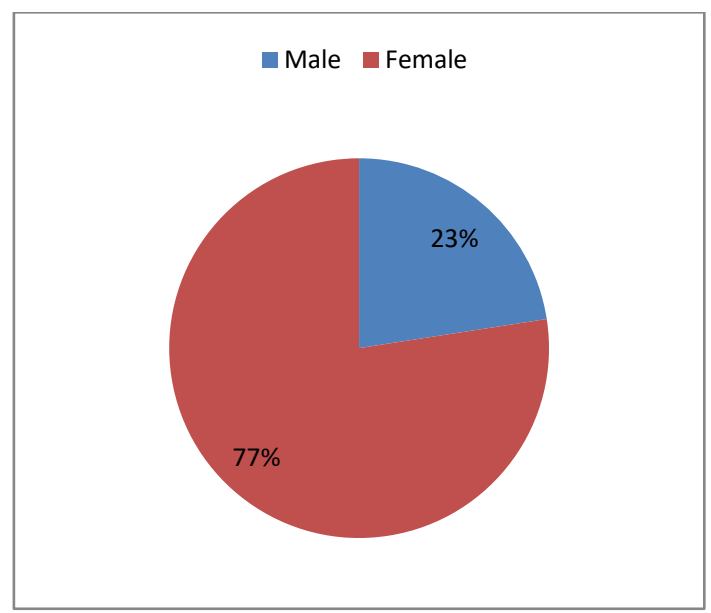

Fig. 3. Gender.

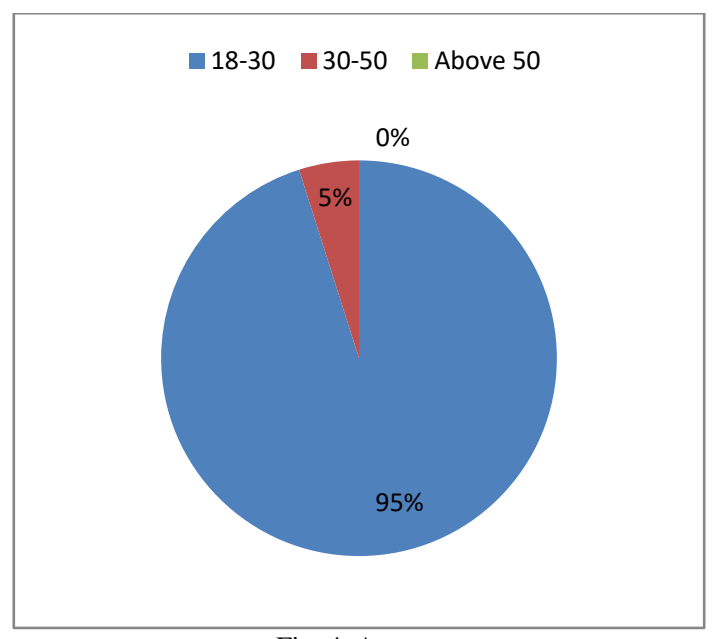

Fig. 4. Age.

1. The opportunities for using AI in the logistics sector in Oman

The below chart shows that $53 \%$ of the respondents agreed that $25 \%$ were strongly approved that $\mathrm{AI}$ is efficient in the logistics sector in Oman. A neutral group of $16 \%$ of respondents were impartial that $\mathrm{AI}$ is efficient in the logistics sector in Oman. On the other hand, the minority of respondents were disagreed and strongly disagreed. They represent 3\% disagree and 3\% strongly disagree of the total respondents. It concludes that using AI in the logistics sector in Oman will increase the efficiency of this sector and make it more developed.

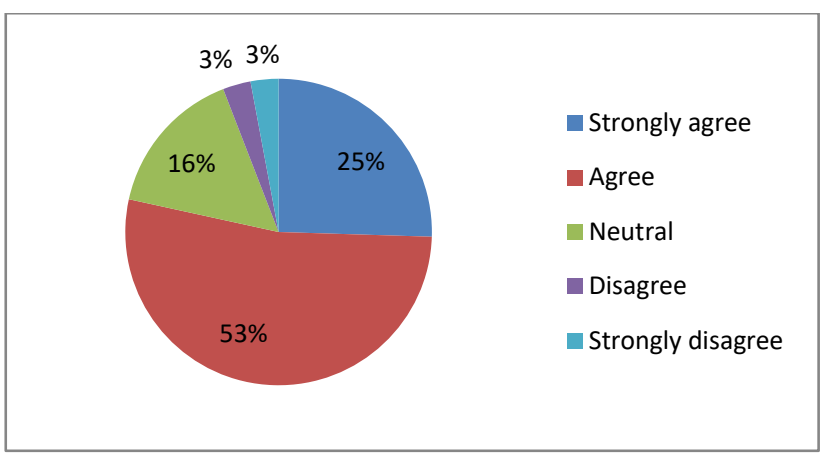

Fig. 5. The efficiency of AI in the logistics sector in Oman.

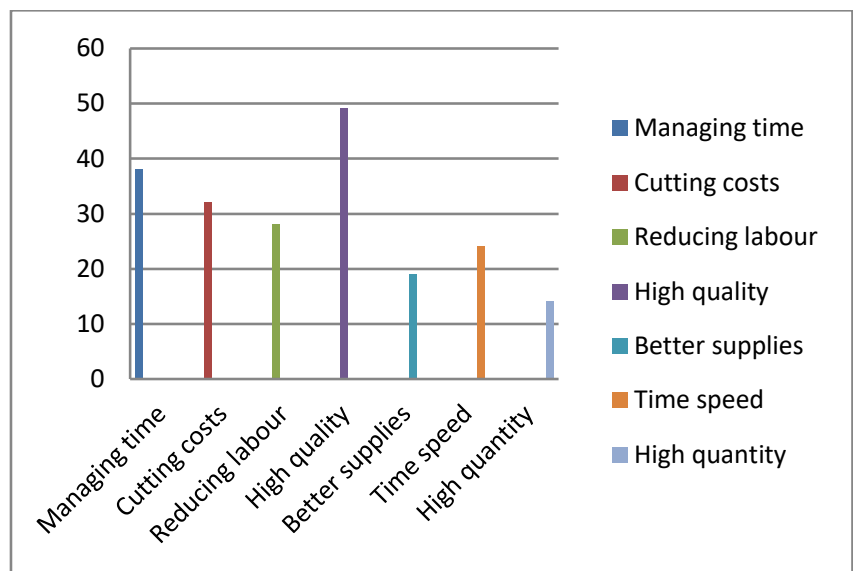

Fig. 6. The advantages of using artificial intelligence in the logistics sector.

This chart outlines the most advantages of using AI in the logistics sector and includes seven benefits with the number of respondents. As shown, most respondents, for about 49 votes, considered that one of the most advantages of using AI is the high quality. Whereas the managing time advantage comes in the second rank, it occupies 38 votes, and the third rank was 32 votes favouring cutting costs edge. Moreover, 28 respondents give their voices to the reducing labour advantage, and 24 of the votes go to the time speed advantage. The monitory votes go to better supplies and high quantity advantages, and they carry about 19 and 14 respectively. It concludes that using AI will help companies increase their services level with high quality, which will help improve the efficiency and productivity within the logistics companies. That will appear positively with the clients who will be provided with satisfying services. Furthermore, when companies improve their quality of services, this will also help achieve other advantages of using AI, managing time, cutting costs, reducing labour, time speed, better supplies, and high quantity advantage.

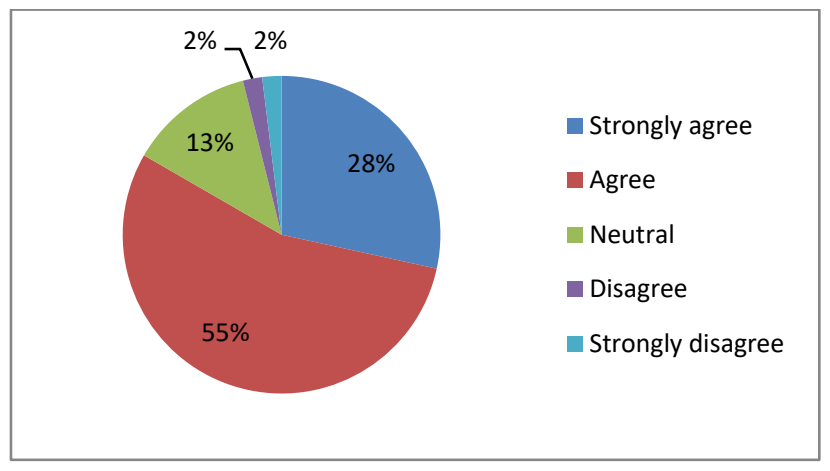

Fig. 7. contributing to the growth of income sources. 
The above chart shows that most respondents who carried a percentage of $55 \%$ were agreed that AI could contribute to the growth of income sources, including the logistics sector. In comparison, $28 \%$ were strongly agreed with that statement. At the same time, a neutral group of $13 \%$ of respondents were impartial that AI could contribute to the growth of income sources, including the logistics sector. On the other side, $2 \%$ have disagreed, and $2 \%$ were strongly disagreed with that statement. So, this figure shows how AI can help increase the income sources in different sectors in Oman. The logistics sector is one of these sectors that can diversify sources using AI technologies. When logistics companies use AI, that can increase their productivity and profitability, which can positively affect the efficiency of the logistics sector.

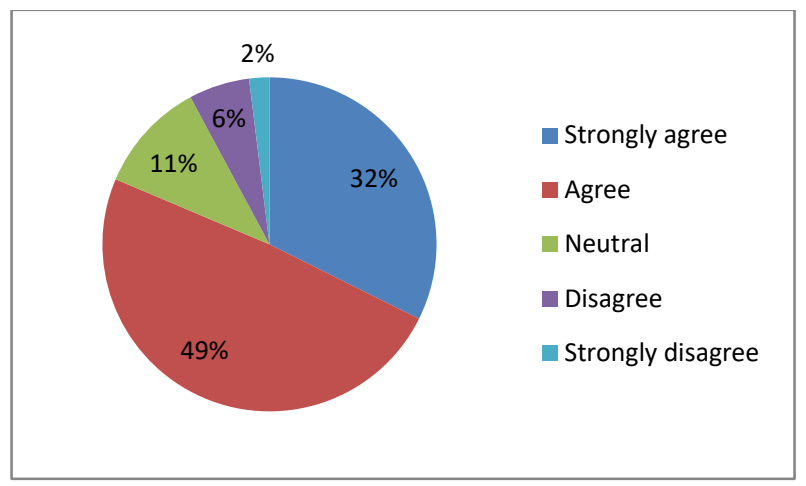

Fig. 8. Contributing to the growth of Oman's economy.

In this chart, most of the responses presented $46 \%$ and $32 \%$ agreed and strongly agreed that AI could contribute to Oman's economy. $18 \%$ of respondents were neutral about the statement. The minority of respondents were disagreed and strongly disagreed. They represent $6 \%$ disagree and $2 \%$ strongly disagree of the total respondents. This figure concludes that AI can contribute to Oman's economy through the logistics sector itself. Where logistics companies can increase the output of this sector, this can increase the country's GDP and improve Oman's economy.

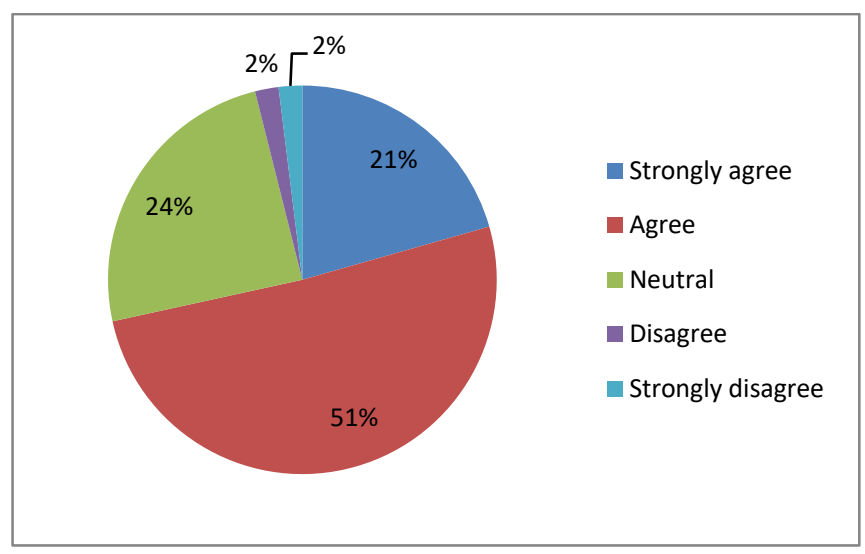

Fig. 9. Reducing the challenges currently facing the logistics sector.

The above chart indicates how AI can reduce the challenges currently facing the logistics sector. Most people agreed with that statement, and they represent $51 \%$, and $24 \%$ of respondents were neutral. More than that, $21 \%$ of respondents strongly agree that $\mathrm{AI}$ could reduce the logistics sector's challenges. On the other hand, few people of respondents were disagreed and strongly disagreed. They represent $2 \%$ and $2 \%$ respectively. Therefore, these large percentages support the literary studies that confirmed that AI could pose the logistics sector's challenges. For instance, one of the biggest challenges that face the logistics sector is the delay in the delivery of cargoes. At the same time, some companies worldwide have already started using autonomous vehicles or self-driving vehicles that can improve the supply chains, reduce the costs and risks of incidents, and speed up delivery.

2. The key challenges facing using AI in the logistics sector in Oman

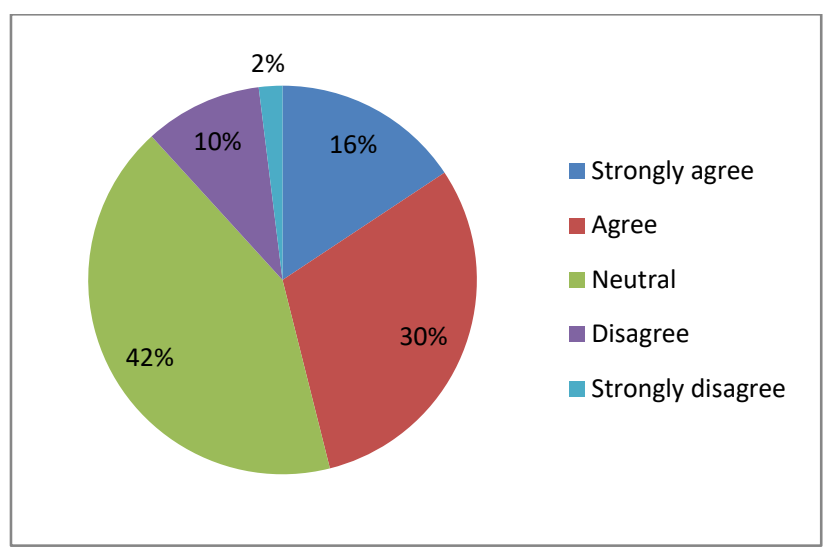

Fig. 10. Unemployment in the logistics sector.

The pie chart illustrates the result of in which if AI will increase unemployment in the logistics sector. It was observed that a high proportion of $42 \%$ of respondents was neutral of that statement. While $30 \%$ of respondents agreed on how AI will increase the unemployment issue in the logistics sector, a proportion of $16 \%$ of respondents strongly agreed. A mere $10 \%$ of respondents disagreed that AI would increase unemployment in the logistics sector, and the tiniest fraction, $2 \%$, of respondents were firmly disagreed. This concludes that AI will impact employment in the logistics sector on two sides. From the positive aspect, AI will create more jobs than it destroys because even if machines could replace human works, the human presence must control it. On the other hand, AI could decrease employment in few places and for different conditions. This can be considered in the interest of the human to alleviate the complex works of the workers like in the warehouses and the opened areas in ports.

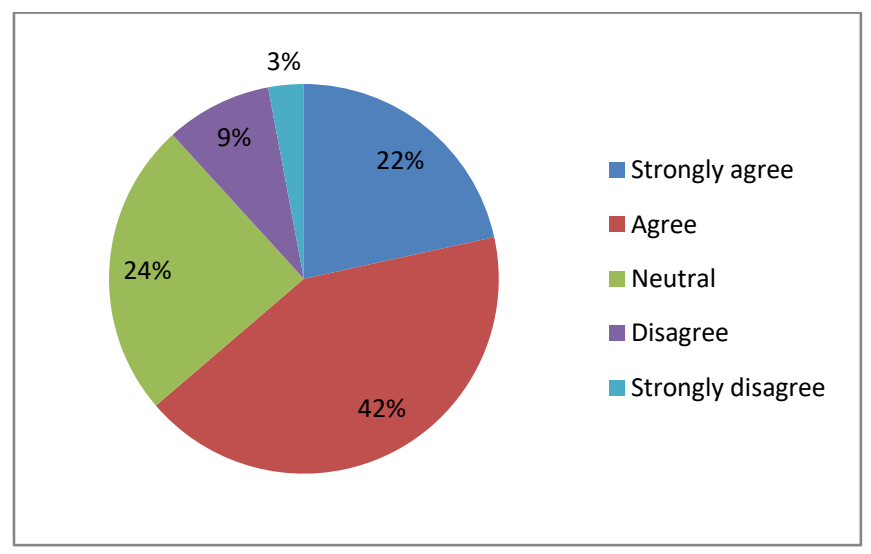

Fig. 11. The extended time for implementation

In general, this chart shows one of the challenges of AI, and it is a long time for implementation. A vast proportion of $42 \%$ was agreed that AI requires a long time for performance, 
and $22 \%$ were strongly agreed. A neutral group of $24 \%$ of respondents were impartial that $\mathrm{AI}$ requires a long time for implementation. On the other hand, the minority of respondents were disagreed and strongly disagreed. They represent $9 \%$ disagree and 3\% strongly disagree of the total respondents. So, the chart concludes that AI has many challenges. One of the most significant challenges that may face $\mathrm{AI}$ in the logistics sector is a long time for implementation because it is a complex machine and needs time and effort for application.

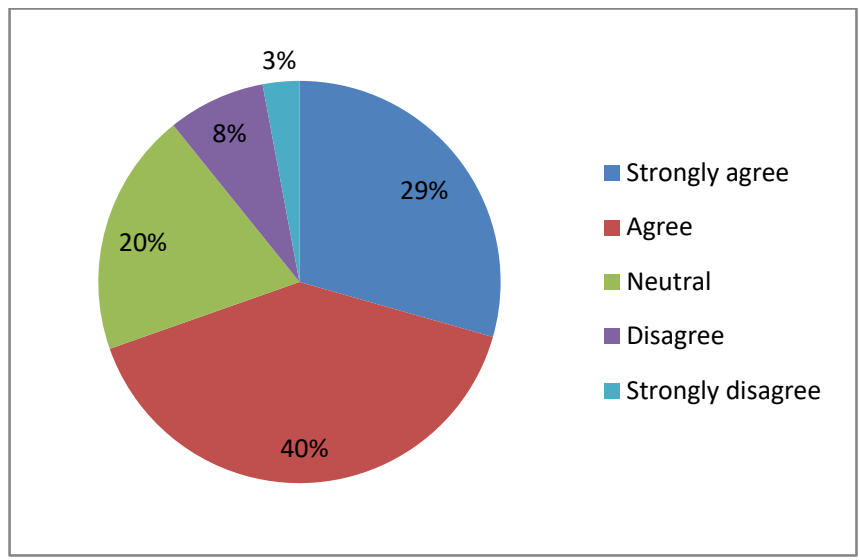

Fig. 12. The high cost of implementation.

Findings of the study revealed that a high proportion of $40 \%$ of respondents was agreed that AI requires a high cost of implementation, and $29 \%$ were strongly agreed. At the same time, a neutral group of $20 \%$ of respondents were impartial that AI requires a high cost of implementation. On the other side, $8 \%$ disagreed, and 3\% were firmly disagreed with that statement. It concludes that $\mathrm{AI}$ is an expensive technology that requires a high cost of implementation because of the complexity of engineering that entering in building one AI machine or system.

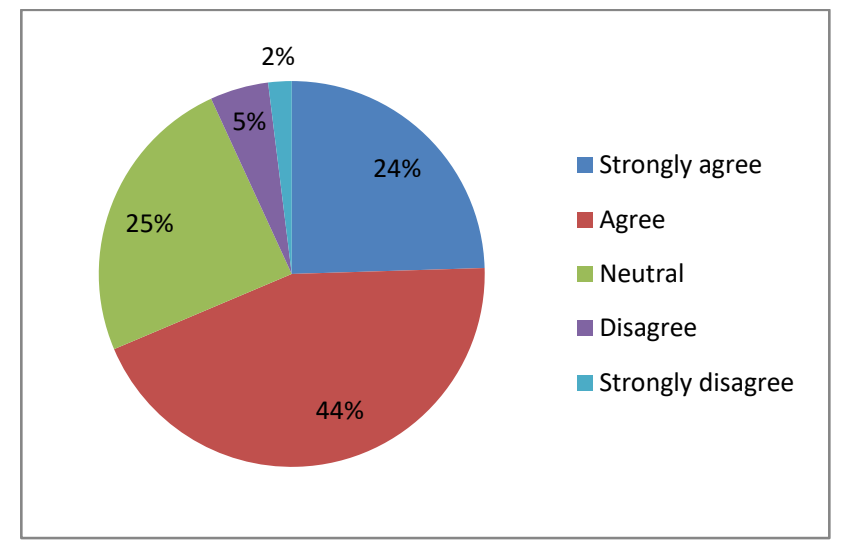

Fig. 13. The potential of artificial intelligence.

The results show that $44 \%$ of respondents agreed that few people are aware of the potential of AI, while $24 \%$ of them were strongly agreed. On the other hand, $25 \%$ of respondents were neutral about the statement. The minority of respondents were disagreed and strongly disagreed. They represent $5 \%$ disagree and $2 \%$ strongly disagree of the total respondents. This figure concludes that many technology enthusiasts, researchers, and college students have only a few people aware of AI potential.

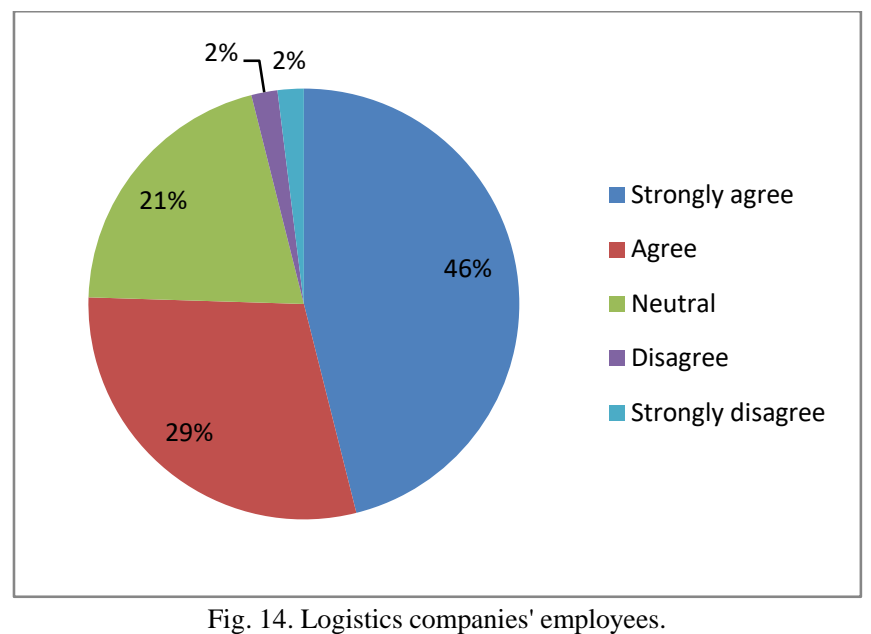

The above chart shows that most respondents who carried $46 \%$ strongly agreed that most logistics companies need more training with new AI skills, while $29 \%$ agreed with that statement. At the same time, there was a neutral group of $21 \%$ of neutral respondents that most logistics companies need more training with new AI skills. On the other side, $2 \%$ disagreed, and $2 \%$ were firmly disagreed with that statement. This result approves that AI will lead to having more training for logistics companies' employees to acquire the new skills of the existing technologies, which is a challenge that would face using $\mathrm{AI}$ in the logistics sector in Oman.

3. The optimal solutions and recommendations to improve using AI in Oman's logistics sector

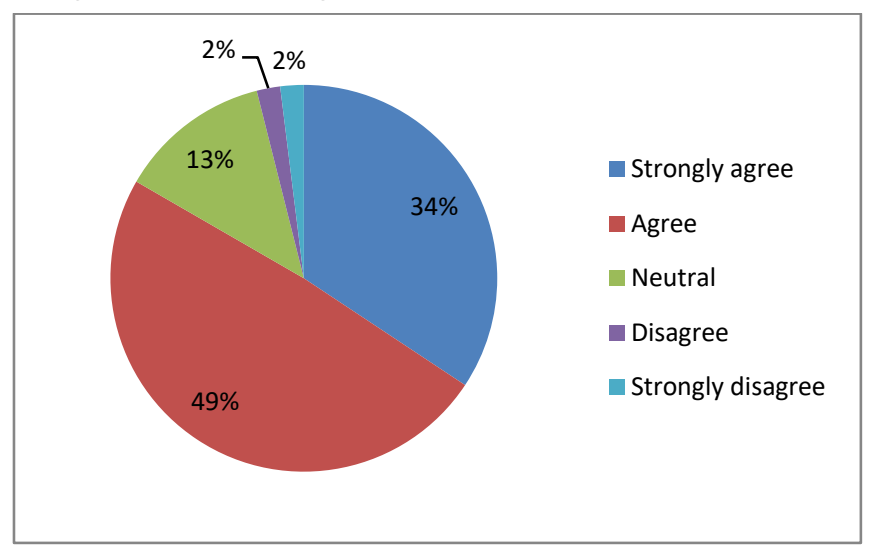

Fig. 15. constructive cooperation between the public and private sectors.

According to the findings, most respondents agreed and strongly agreed that having constructive cooperation between the public and private sectors is one of the most important solutions to improve the use of AI in the logistics sector in Oman. They represent $49 \%$ agree, and 34\% strongly agree of the total respondents. $13 \%$ of respondents were neutral. The minority of the respondents were disagreed and strongly disagreed, and they represent $2 \%$ and $2 \%$, respectively, of the total respondents. So, it concludes that having constructive cooperation between the government and the private sector will help improve the use of AI in the logistics sector and increase the performance of logistics companies which will enhance the logistics sector's efficiency. 


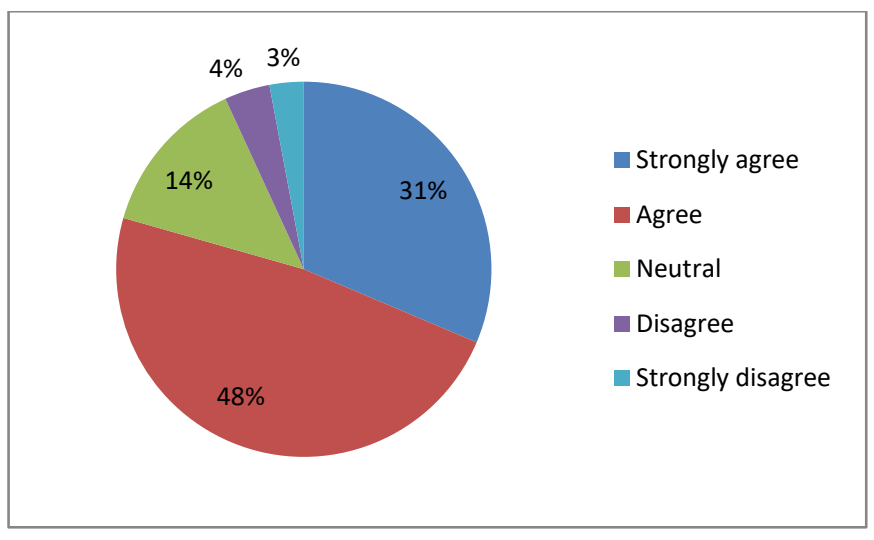

Fig. 16. AI in schools and universities' curricula.

The study reveals that $48 \%$ of respondents agreed that schools and universities should implement AI in their curricula. In comparison, $31 \%$ of respondents were strongly agreed with that statement. $14 \%$ of respondents were neutral that schools and universities should implement AI in their curricula. Other respondents disagreed and strongly agreed, representing $4 \%$ and $3 \%$ respectively of the total respondents. This figure concludes that schools and universities should implement AI in their curricula to create generations powered by technological progress to develop the logistics sector and the country.

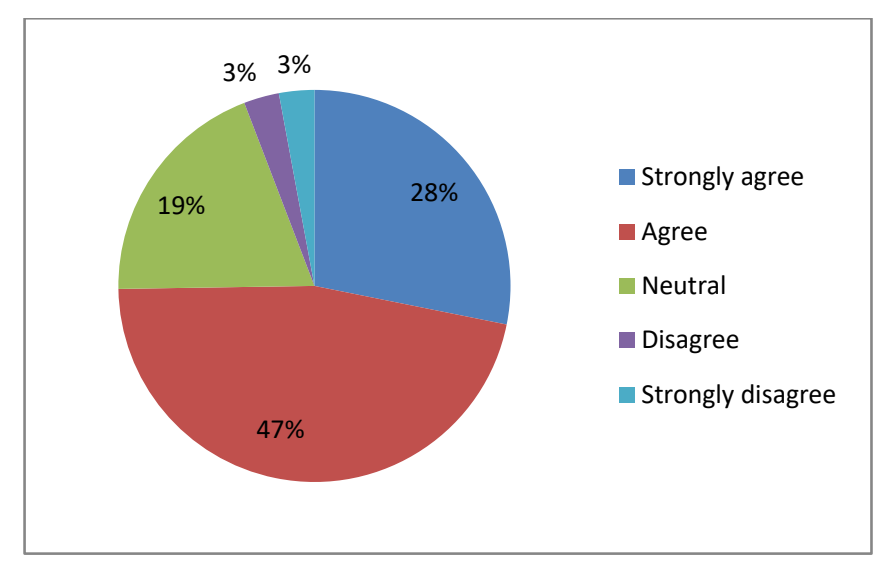

Fig. 17. Ethical sides of $\mathrm{AI}$ in schools and universities.

The above chart shows that $47 \%$ of the respondents were agreed, and $28 \%$ were strongly agreed that Schools and universities should consider the ethical side of AI. A neutral group of $19 \%$ of respondents were impartial that Schools and universities should consider the moral side of AI. On the other hand, the minority of respondents were disagreed and strongly disagreed. They represent 3\% disagree and 3\% strongly disagree of the total respondents. It concludes that schools and universities should include ethics and related topics about AI, ML, computer science, and data science to qualify humans to design, construct, and use machine ethics.

According to respondents' responses, there are many recommendations to improve the use of $\mathrm{AI}$ in the logistics sector in Oman. For instance, working to spread awareness among companies and the private sector in Oman as a basis for the planning process and managing logistics services in Oman, and bringing experts to teach employees how they deal with AI and use simple AI techniques as a preparation step a bright future. Moreover, improving the quality of services in logistics sector companies using new technologies and making more businesses and investment with big logistics companies. Furthermore, spreading the culture of AI between social individuals to be aware of the meaning of AI and how much it is essential to be implemented, and what benefits that all people can gain by using AI. Also, using different types of AI technologies because today the logistics sector leads the market, giving the customers a high quality of services.

Additionally, empowering employees and youth to learn and have skills in this field, implementing ethics in employing people in this area, and giving Omani children the opportunity to contribute to this area and lead the future of Oman. Moreover, increasing intellectual awareness about AI in the logistics sector and providing financial capacity for AI without consequences for logistics companies. Also, AI should not be relied upon to a large extent so that there is no unemployment in society.

\section{CONCLUSIONS AND RECOMMENDATIONS}

This chapter summarises the research study, which evaluates the advantages and disadvantages of using AI in Oman's logistics sector. The researcher concludes the findings based on the results obtained from chapter four. Besides that, the researcher also gives recommendations for future research to improve the use of $\mathrm{AI}$ in the logistics sector in Oman.

\section{A. Conclusions}

The main objective of this study is to investigate the impact of using AI in the logistics sector in Oman. The study also aimed to identify the opportunities for using AI in the logistics sector in Oman, the issues surrounding using AI in the logistics sector in Oman and recommend possible solutions to improve the use of $\mathrm{AI}$ in the logistics sector in Oman. Based on the previous chapter, the outcomes and discussions have been identified.

The outcomes of the first objective, identifying the opportunities for using AI in the logistics sector in Oman. The results obtained from previous reviews indicated that $\mathrm{AI}$ could help improve the efficiency of the logistics sector and reduce the challenges currently facing the logistics sector. AI can provide different advantages to logistics companies, including high quality, managing time, cutting costs, reducing labour, time speed, better supplies, and high quantity advantage. The role of that will appear in diversifying the income sources and contribute to the growth of Oman's economy.

The outcomes of the second objective, identifying the issues surrounding using AI in the logistics sector in Oman. The results obtained from questionnaire, interviews, and articles indicated the most significant challenges that may result surrounding using AI in the logistics sector in Oman are unemployment, the extended time for implementation, the high cost of implementation, lack of awareness of the potential of $\mathrm{AI}$, and requiring training with acquiring new skills of AI.

The outcomes of the third objective recommending possible solutions to improve the use of AI in the logistics sector in Oman. Based on the findings, participants and interviewees suggest many recommendations to improve the 
use of AI in the logistics sector in Oman, such as people in the society should have an awareness of AI potential, and educational institutions must provide students with the concept of AI in curricula. Training employees to acquire new skills to adapt to AI.

\section{B. Recommendations}

The study has been conducted to investigate the impact of using AI in the logistics sector in Oman. As the investigation progressed, the researcher has reached ideal suggestions to improve the use of AI in the logistics sector in Oman. The recommendations are as follows:

1. Logistics companies should train their employees to use $\mathrm{AI}$ in various supply chains to be equipped with more knowledge and skills in a creative path.

2. Government and private companies should examine how they can benefit from AI in trajectories that can help society.

3. Educational institutions should implement AI in their curricula and concentrate more on the practical side of applying AI for students to create generations powered by technological progress to develop the logistics sector and the country.

4. The Ministry of Higher Education should establish institutes specialised in educating about AI to qualify individuals with sufficient experience by the latest developments in the AI field.

5. Spreading the culture of AI between individuals in the community to be aware of the potential of AI and how much it is essential to be implemented, and what benefits that all people can gain by using AI.

6. Logistics companies should combine humans and machine learning automation with their environment to assess data to have a high quality and achieve high performance when the human staff and machine work together.

7. Transportation companies should use the latest delivery management systems in conveying shipments to the clients in the shortest possible time.

8. Logistics and customs clearance companies should rely more on modern systems in clearing transactions to gain customer satisfaction and improve services with high quality.

9. The intensification from robots and other AI technologies in factories, warehouses, and retail stores can reduce time, cost, and effort in several operations and activities, including sorting, packing, packing, organising, shipping, and many others.

10. Ports' authorities should provide the port environment with the most modern machinery and systems to increase the operations performance, productivity and attract more customers.

11. The public and private sector should understand the nature of the labour market where AI should be implemented in a path that repurposes the power in the labour market rather than makes it redundant.

\section{APPENDIX}

Questionnaire questions link: $\mathrm{hW}$ -

https://forms.office.com/Pages/ResponsePage.aspx?id=Pa

pA0mkaK26N_479WhpB70_1YgyFIkmyJM64y5zBUQldV

\section{WUFTWkpYSVAwVIRaMlpYVIZUWEJaSi4u}

Interview questions link:

https://forms.office.com/Pages/ResponsePage.aspx ?id=Pah W-

pA0mkaK26N_479WhpB70_1YgyFIkmyJM64y5zBUQjQx M0Q0RFIPUIBRMkJIVVJWMIVDT1BNVC4u

\section{ACKNOWLEDGMENT}

In the beginning, I thank God for giving me the inspiration and ability to complete this research.

I would like to extend my sincere gratitude and thanks to Mr Zouhaier Slimi, a lecturer at the International Maritime College Oman and supervisor for this research for the continuous and unlimited support, guidance, and motivation.

Furthermore, I would like to thank employees of logistics companies and students from other colleges and universities who contributed effort, motivation, vital advice, and support.

Thanks also go to the interviewers, who gave their valuable time to participate in this study.

In the end, special thanks to my family, who are beyond my inspiration and motivation.

\section{REFERENCES}

[1] A. Bundy, "Preparing for the future of Artificial Intelligence," Ai Soc. vol. 32, no. 2, pp. 285-287, 2017, DOI: 10.1007/s00146-01DOI685-0

[2] R. Ashri, "What Is AI?," AI-Powered Work., pp. 15-29, 2020, DOI: 10.1007/978-1-DOI2-5476-9_2.

[3] Y. Zhang, "The application of artificial intelligence in logistics and express delivery," J. Phys. Conf. Ser., vol. 1325, no. 1, 2019, DOI: 10.1088/1742-6596/1325/1/012085.

[4] L. Benton, "6 Ways Artificial Intelligence Technology Is Impacting Logistics and Supply Chain Management - Supply Chain 24/7," 2018. https://www.supplychain247.com/article/6_ways_artificial_intelligenc e_technology_is_impacting_the_supply_chain (accessed Dec. 10, 2020).

[5] J. Larson and H. Tamimi, "Maximising Artificial Intelligence opportunities in Oman - Oman Observer," 2019. https://www.omanobserver.om/article/24549/Business/maximisingartificial-intelligence-opportunities-in-oman (accessed Mar. 12, 2021)

[6] Saranya and Phil, "A Study on Artificial Intelligence Technologies and its Applications," Int. J. Sci. Res. Comput. Sci. Eng. Inf. Technol., vol. 5, no. 4, pp. 336-344, 2016, doi: 10.32628/cseit206455.

[7] K. Spirina and A. Zharovskikh, "AI in Logistics and Transportation InData Labs," 2020. https://indatalabs.com/blog/ai-in-logistics-andtransportation?cli_action $=1615143779.008$ (accessed Mar. 07, 2021).

[8] C. Peters, "5 Ways AI Will Transform the Logistics Industry AltexSoft," 2018. https://www.altexsoft.com/blog/business/5-ways-aiwill-transform-the-logistics-industry/ (accessed Mar. 07, 2021).

[9] M. Makadia, "Artificial Intelligence in Logistics - Maximising Operational Efficiency - Business 2 Community," 2020 https://www.business2community.com/business-innovation/artificialintelligence-in-logistics-maximizing-operational-efficiency-02369850 (accessed Mar. 08, 2021).

[10] Atheer, "An Asyad official explains about modern logistical technologies," 2020. https://www.atheer.om/archives/523951/ (accessed Mar. 12, 2021).

[11] A. Das, "What are the disadvantages of AI?" 2019 https://www.proschoolonline.com/blog/what-are-the-disadvantagesof-ai (accessed Dec. 12, 2020).

[12] G. Popovici, "Robots Shall Not Replace Humans, Robots Shall Make Humans," Robot. Manag., vol. 22, pp. 1-4, 2018.

[13] Redwood Logistics, "The Top Challenges that Occur with AI (Artificial Intelligence) in Logistics - Redwood Logistics : Redwood Logistics," 2018. https://www.redwoodlogistics.com/top-challengeswith-ai-in-logistics/ (accessed Dec. 12, 2021).

[14] McKinsey Global Institute, "What the future of work will mean for jobs, skills, and wages: Jobs lost, jobs gained | McKinsey," 2017. https://www.mckinsey.com/featured-insights/future-of-work/jobs- 
lost-jobs-gained-what-the-future-of-work-will-mean-for-jobs-skillsand-wages (accessed Dec. 12, 2020).

[15] S. A. Al-Salti, "Artificial intelligence is a double-edged sword," 2019. https://www.atheer.om/archives/492433/ (accessed Mar. 13, 2021).

[16] P. Vadapalli, "Top 7 Challenges in Artificial Intelligence in 2021 upGrad blog," 2021. https://www.upgrad.com/blog/top-challenges-inartificial-intelligence/ (accessed Mar. 14, 2021).

[17] W. Wang and K. Siau, "Artificial intelligence, machine learning, automation, robotics, future of work and future of humanity: A review and research agenda," J. Database Manag., vol. 30, no. 1, pp. 61-79, 2019, DOI: 10.4018/JDM.2019010104.

[18] S. A. D. Popenici and S. Kerr, "Exploring the impact of artificial intelligence on teaching and learning in higher education," Res. Pract. Technol. Enhance. Learn., vol. 12, no. 1, 2017, DOI: 10.1186/s41039017-0062-8.

[19] PixelPlex, "How Using Artificial Intelligence (AI) in Business Can Improve Efficiency," 2020. https://pixelplex.io/blog/use-cases-of-aiin-business/ (accessed Mar. 15, 2021).

[20] Alex, "research methods- mixed methods - Advantages and disadvantages table in A Level and IB Sociology," 2013. https://getrevising.co.uk/grids/research_methods_mixed_methods (accessed Apr. 18, 2021).

[21] Rahman, "Advantages and disadvantages of questionnaires," 2020. https://howandwhat.net/advantages-disadvantages-questionnaires/ (accessed Mar. 24, 2021).

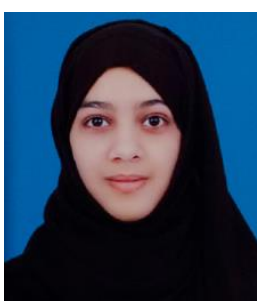

Khadija Hassan Almaqbali Born 06011998 in Sohar the Sultanate of Oman. Holder of BA in Logistics and Transportation Management from the International Maritime College Oman.

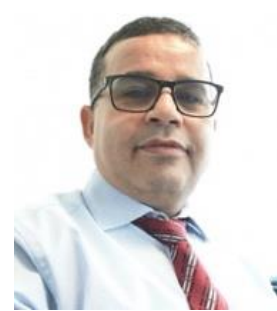

Zouhaier Slim is a $\mathrm{PhD}$ student at Deusto University/Spain Department of Education and Psychology. MA in the Arts of Learning and Teaching Roehampton/UK. TESOL certified from ITTT, B.A in English Language and Literature Sousse/Tunisia. Member of European Journal of Educational Science, EJES reviewal team.

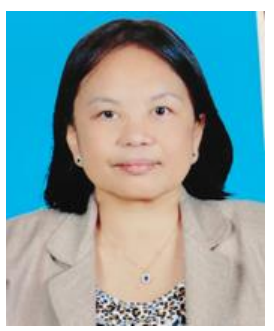

Ms Balasa is a Doctor of Public Administration (DPA), The University of Manila, Philippines, October 2002. She is presently working as an Associate Professor of Economics at Intranational Maritime College Oman, Sohar, Sultanate of Oman, from February 2009. 